\title{
UNUSUAL DISSEMINATION PATTERNS OF LOW-GRADE ASTROCYTOMAS IN CHILDHOOD
}

\author{
Patricia Imperatriz Porto Rondinelli', Carlos Alberto Martinez Osório', \\ Marcela Pécora Cohen'2, Paulo Eduardo Ribeiro Santos Novaes ${ }^{3}$
}

\begin{abstract}
Context: Low-grade astrocytomas are intracerebral lesions of relatively high frequency in the under18 pediatric population. They often present indolent behaviour, and complete surgical resection is the choice treatment. In cases where the surgery is not possible, chemotherapy and radiotherapy may be used. Medical reports do not recommend examination of the spinal cord at diagnosis or during treatment, since the risk of dissemination of the lesion to the spine is minimal according to medical experience. We describe here four cases of children with low-grade astrocytoma with aggressive dissemination to the neuroaxis.
\end{abstract}

KEY WORDS: astrocytomas, pilocytic astrocytoma, brainstem tumor, brain neoplasms, children.

\section{Padrões incomuns de disseminação dos astrocitomas de baixo grau na infância}

Resumo - Contexto: Gliomas de baixo grau de malignidade são lesões intracerebrais relativamente freqüentes na população pediátrica menor de 18 anos de idade. Eles freqüentemente são indolentes em seu comportamento e a ressecção cirúrgica completa é o tratmento de eleição. Nos casos em que a cirurgia não é possível, a quimioterapia e a radioterapia podem ser utilizadas. Relatos da literatura não recomendam a avaliação radiológica da coluna espinhal ao diagnóstico ou durante o tratamento, desde que o risco de disseminação destas lesões para a coluna é considerado mínimo. Descrevemos aqui quatro casos de crianças com gliomas de baixo grau de malignidade com disseminação agressiva para o neuroeixo.

PALAVRAS-CHAVE: astrocitomas, astrocitoma pilocítico, tumor de tronco cerebral, tumor cerebral, criança.

Combined different factors have contributed to higher survival rates among patients with low-grade astrocytomas (LGA). Tumor anatomical site, growth rate and invasiveness, along with more accurate histological diagnosis, have lead oncologists and neurosurgeons to properly tailor therapeutic approaches in each case. A growing number of individuals survive LGA. Despite tumor surgical resection cannot be always achieved, many children may live for long periods of time while bearing glial brain lesions. During somatic growth of affected children, tumour cells mutations may occur. A variety of poorly understood factors are possibly involved in dissemination or progression of low- to high-grade astrocytoma (HGA), and there are no available data in medical literature that estimate the frequency of these situations. Paucity of figures might be due to short follow-up of patients, until their adulthood, in recently created Pediatric Oncology Units.

We describe and comment four cases of LGA patients with unexpected tumor dissemination through the entire neuroaxis. No one of the patients had a genetic syndrome.

\section{CASES}

Case 1

A 5 years old boy, with a brainstem tumor, with characteristics suggestive of pilocytic astrocytoma (Fig 1). No surgery was done because the risk of surgical procedure in this anatomic region of brain. Seven months after local radiotherapy with 54 Gy doses, and under oral treatment with $150 \mathrm{mg} / \mathrm{m}^{2} /$ day temozolomide for 5 days/cycle, he developed extensive intraspinal tumor, from the first cervical to the first sacral vertebrae (Fig 2). The patient died one month after diagnosis of the dissemination process.

\section{Case 2}

A 16 years old boy, presenting with primary brain stem tumor with image results suggestive of pilocytic LGA (Fig 3). The patient

Hospital A.C. Camargo, São Paulo SP, Brazil: 'Department of Pediatrics; ${ }^{2}$ Department of Radiology; ${ }^{3}$ Department of Radiotherapy.

Received 26 June 2007, received in final form 20 September 2007. Accepted 9 November 2007.

Dra. Patricia Imperatriz Porto Rondinelli - Hospital AC Camargo - Rua Professor Antônio Prudente 211 - 01509-900 São Paulo SP - Brasil. E-mail: patrondinelli@terra.com.br 


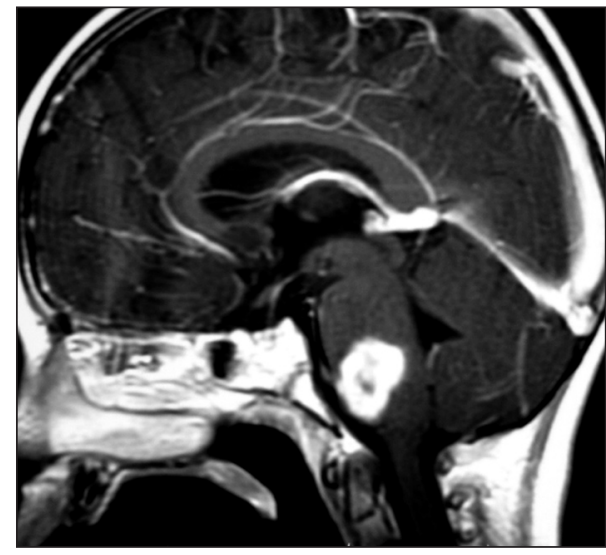

Fig 1. MRI: median sagittal T1-weighted section, enhanced with paramagnetic contrast (gadolinio), shows well-delimited solid lesion in the brainstem (between the pontine and medulla oblonga), with intense highlight of the lesion due to the paramagnetic contrast.

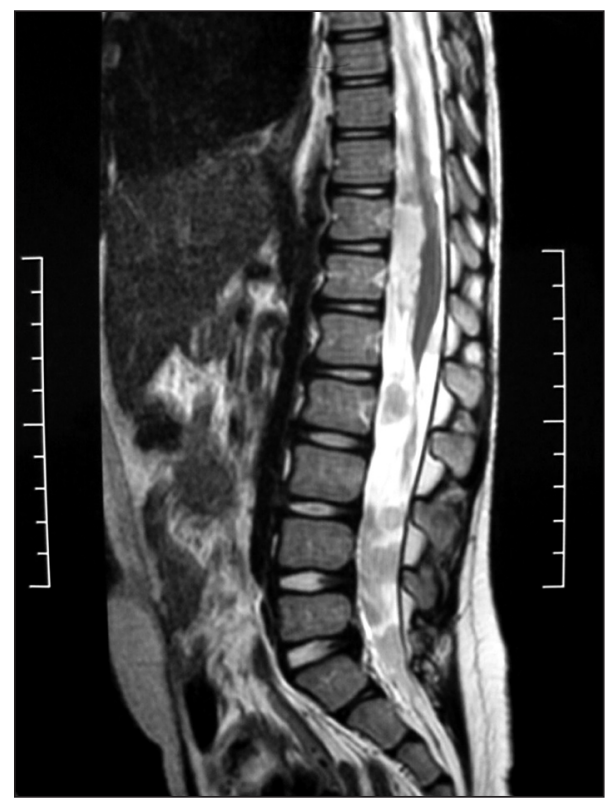

Fig 2. Thoracolombar spine MRI: T2-weighted section shows multiple intradural and extramedullary nodular lesions of intermediate signal, that shift the position and deform the cone and spinal cord.

received 54 Gy radiotherapy and cycles of $150 \mathrm{mg} / \mathrm{m}^{2} /$ day temozolomide for 5 days every 28 days. Neuroaxis dissemination was observed after 10 cycles of the drug (Fig 4), and the patient died five days later after the diagnosis of dissemination.

\section{Case 3}

A 5 years old boy, with a pilocytic astrocytoma in the $\mathrm{Cl}-\mathrm{C} 2$ transition diagnosed at age 8 months by biopsy (Fig 5). The patient was submitted at diagnosis to local 45 Gy radiotherapy and to six cycles of chemotherapy $\left(300 \mathrm{mg} / \mathrm{m}^{2} /\right.$ day carboplatin at D1 and $150 \mathrm{mg} / \mathrm{m}^{2} /$ day etoposide at D1-D3 of each cycle). The

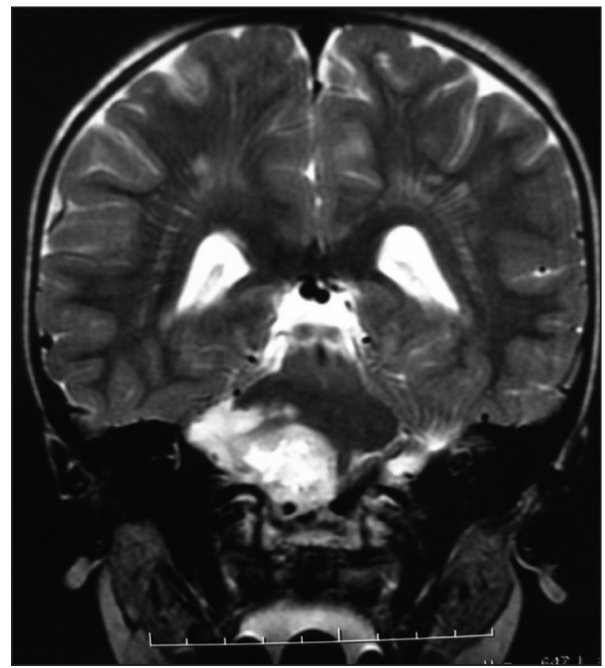

Fig 3. MRI: sagittal T2-weighted section shows lesion with heterogeneous hyposignal and lobulate borders in the pontine/cerebellar peduncle.

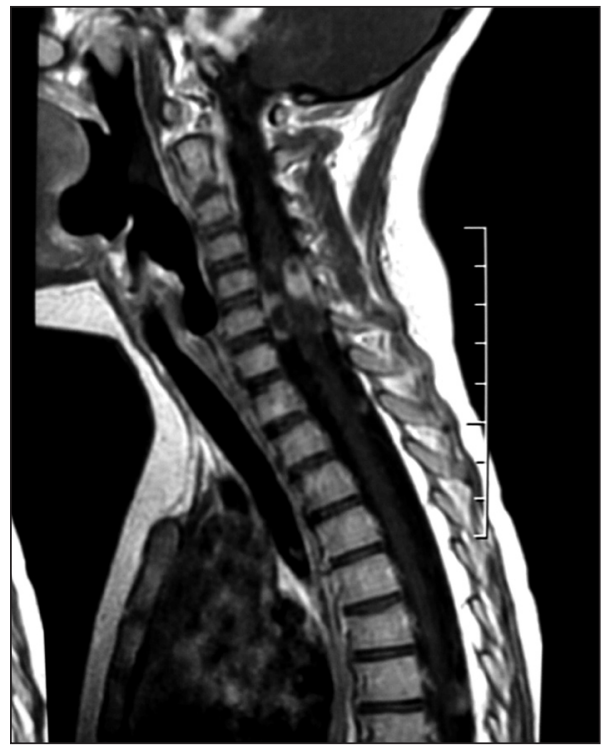

Fig 4. Cervicothoracic spine MRI: sagittal T7-weighted section with shows lesions that widen the dural at the C5-C6 level, enhanced by the paramagnetic contrast. residual lesion was stable for 7 years, when the patient started with lower back pain. Medical examination showed tumor cells in the cerebrospinal fluid (CSF) and neuroaxis dissemination (Fig 6). Weekly administration of $175 \mathrm{mg} / \mathrm{m}^{2} /$ day carboplatin and 1.5 $\mathrm{mg} / \mathrm{m}^{2} /$ day vincristine was started and recent evaluation, nine months after beginning of treatment, showed no tumor cells in CSF, as well as clinical and radiological improvement with partial response of the spinal lesions. Different of the cases 1 and 2 , we have used carboplatin and vincristine in this patient because temozolamide was not available in Brazil on the time of the treatment. 


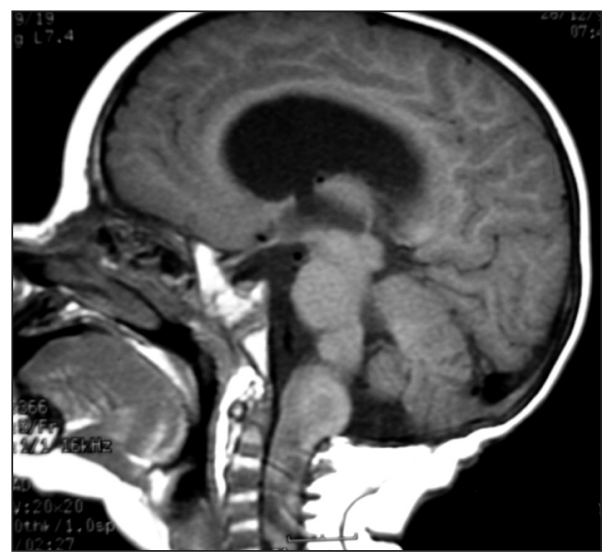

Fig 5. MRI: median sagittal T1-weighted section without contrast shows lesion of intermediate signal in the cervical spine, with curvature of the cervical spine and upper dislocation of the brainstem.

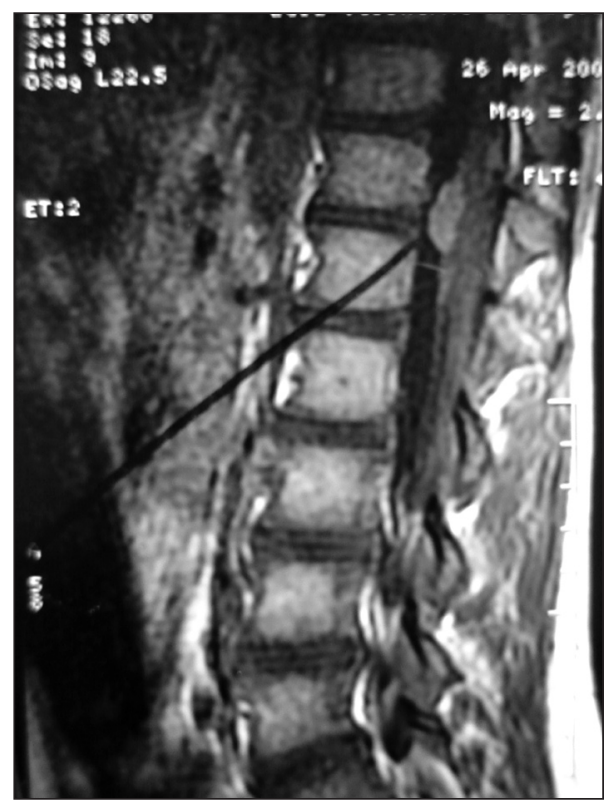

Fig 6. Thoracolombar spine MRI: sagittal T7-weighted section shows lesion of intermediate signal, at the D11-D12 transition on the dural sac, protruding to the epidural fat.

\section{Case 4}

A 6 years old boy, presented with a diffuse astrocytoma of the thalamus confirmed by stereotaxic biopsy (Fig 7), developed paraplegia immediately after a neurosurgery for correction of an external ventricular derivation. MRI investigation of the spinal cord showed extensive dissemination to the neuroaxis (Fig 8). The patient died 36 hours after surgery presenting a seizures of difficult medical control.

\section{DISCUSSION}

Brain gliomas with leptomeningeal dissemination, found in association with almost all LGA subtypes, are

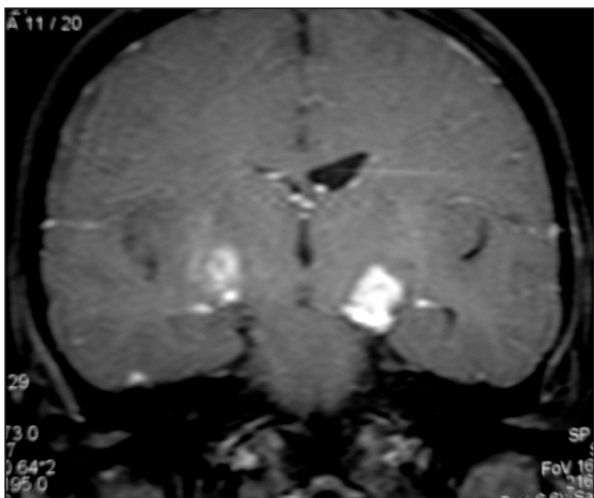

Fig 7. MRI coronal T1-weighted image of the brain, after intravenous injection of the paramagnetic contrast, shows asymmetry with reduction of the frontal horn of the lateral ventricle and areas of abnormal enhancement in the left ambiens cistern region.

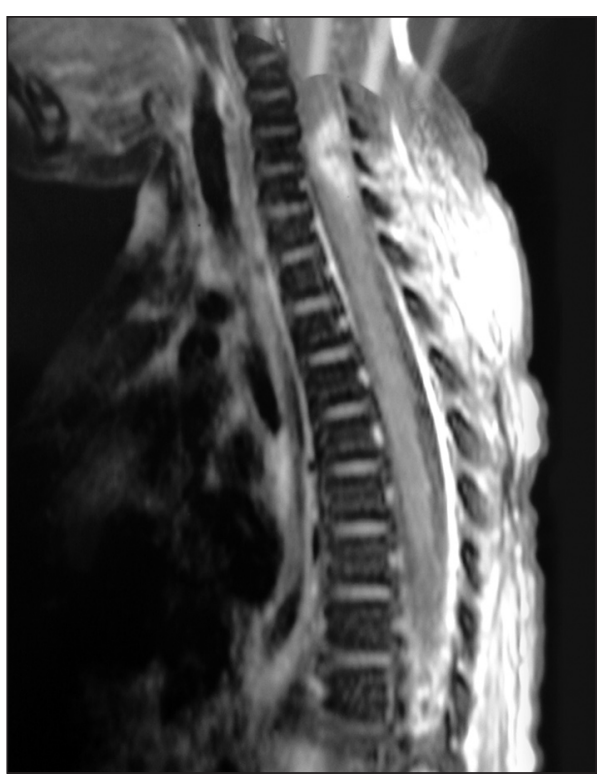

Fig 8. MRI sagittal, contrast-enhanced T7-weighted image of the cervicothoracic spine shows areas of abnormal enhancement around T2-T5 vertebral bodies. currently more frequent among patients of Pediatric Oncology Units. It is estimated that only $5 \%$ to $10 \%$ of LGA may disseminate to leptomeninges, much more frequently at the time of progression than at diagnosis'.

There are three possible outcomes for patients with residual intracerebral LGA. The lesion may remain unchanged, may progress to a high-grade tumor or, more rarely, may disseminate to the entire central nervous system. Although LGA seem indolent tumors, they are not benign and may occasionally become fatal. Besides infiltrating adjacent structures, the cells may acquire ge- 
netic mutations that induce their anaplastic progression to high-grade astrocytomas. It has been suggested that around $50 \%$ to $70 \%$ of these tumors constitute high-grade lesions when dissemination occurs ${ }^{2-4}$. Anaplastic astrocytomas and multiforme glioblastomas are considered by the World Health Organization (WHO) as grade III and IV lesions, respectively. They can have a de novo origin, i.e. may originate from normal brain tissues, or originate from a residual brain lesion, often a LGA. In this case, diffuse astrocytomas are more frequently involved than pilocytic astrocytomas, WHO grade II and I lesions, respectively.

The probability of dissemination of a LGA to the spinal cord is so low that the medical literature does not recommend routine investigation of this anatomical site by MRI or even CSF collection at diagnosis. There are few reports of patients who had LGA in childhood and later presented dissemination to the entire neuroaxis. In cases 1 and 2, for instance, we would not have expected primary low-grade tumors of the brainstem to disseminate to the spinal cord. It is possible that administration of oral temozolamide in these two cases influenced the dissemination process, since prolonged used of the drug increases survival of the patient, interfering with the natural history of the disease ${ }^{5}$.

Tarnaris et al. described the case of a 5-year old boy presenting with pontine glioma, in which leptomeningeal metastases were already present at diagnosis but were not detected by the radiological and cytological initial examinations ${ }^{6}$. Initial image examination of cases 1 and 2 suggested pilocytic astrocytomas, but unfortunately histological confirmation was not possible, due to the anatomical risk of sampling the brainstem. There are few information about the incidence and biological behavior of supratentorial pilocytic astrocytomas in children ${ }^{7}$. Prognosis is in general highly favorable, with a $95 \%$ probability of survival in five years. The rare cases of leptomeningeal dissemination reported presented unfavorable outcome ${ }^{8}$. Recent studies have identified some of the factors which can predispose to leptomeningeal dissemination of pilocytic astrocytomas. These factors include location of the tumor in the region of the optic chiasm - hypothalamus, and/or the presence of type 1 neurofibromatosis syndrome, and/or biopsy or partial resection of the tumor.

Dissemination may also be part of the natural history of the tumor in case it is not treated ${ }^{9}$. Case 3 was really unexpected. Dissemination of a pilocytic astrocytoma which had been latent for 7 years to the spinal cord has been rarely described. Clinical and radiological responses followed by CSF remission are also original findings in the medical literature.

There are only five reports of leptomeningeal dissemi- nation of pilocytic astrocytomas at diagnosis. Figueiredo et al. have recently described two cases ${ }^{9}$. Zorlu et al. described the case of a 4-year old girl with signs of leptomeningeal dissemination consequent to subtotal resection of a pilocytic cerebellar astrocytoma ${ }^{10}$. A case similar to ours was reported by Mishima et al., involving a 6-year old boy with totally removed pilocytic cerebellar astrocytoma and receiving 30 Gy radiotherapy. Six years after the initial surgey, leptomeningeal dissemination (multiple nodules, tumor masses but no evidence of cerebellar recurrence) was observed. Cytological examination of CSF was negative. After biopsy, histological analysis showed that the disseminated tumor was identical to the original tumor". Other two cases of pilocytic hypothalamic astrocytomas were described by Buschmann et al. The patients presented with leptomeningeal dissemination synchronic with the tumor ${ }^{8}$.

Case 4 of the present work describes a patient with diffuse astrocytoma of the thalamus, with extensive leptomeningeal dissemination at initial diagnosis which was accidentally found. Leptomeningeal dissemination of LGA is so rare that no treatment protocol for the situation is currently under evaluation. The ideal treatment is still under discussion ${ }^{12,13}$, but it has been suggested that chemotherapy instead of radiotherapy should be initially used ${ }^{8}$.

Dissemination of low-grade glial lesions to leptomeningeals, at diagnosis or during tumor progression, has been observed with increased frequency, possibly because of a modification of the natural history of the tumor or due to more efficient clinical observation and image examination. These findings suggest that all patients with low-grade gliomas, particularly with lesions near the hypothalamus and/or brainstem, should be more carefully examined. These results may contribute to the understanding of the biological behavior of these tumors and to possibly modify the diagnostic investigation and therapeutic approach.

In conclusion, leptomeningeal dissemination of LGA is unusual, but has been reported with increased frequency at the diagnosis of the primary cerebral tumor, suggesting that all patients with low-grade gliomas, and particularly those with lesions near the hypothalamus and brain stem, should be submitted to careful examination of the lesions with image techniques.

\section{REFERENCES}

1. Perilongo G, Garrè ML, Giangaspero F. Low-grade gliomas and leptomeningeal dissemination: a poorly understood phenomenon. Childs Nerv Syst 2003;19:197-203.

2. Leighton C, Fisher B, Bauman G, et al. Supratentorial low-grade glioma in adults: an analysis of prognostic factors and timing of radiation. J Clin Oncol 1997;15:1294-1301.

3. Olson JD, Riedel E, DeAngelis LM. Long-term outcome of low-grade oligodendroglioma and mixed glioma. Neurology 2000;54:1442-1448. 
4. Cavaliere R, Lopes MB, Schiff D. Low-grade gliomas: an update on pathology and therapy. Lancet Neurol 2005;4:760-770.

5. Broniscer A, Iacono L, Chintagumpala M, et al. Role of temozolomide after radiotherapy for newly diagnosed diffuse brainstem glioma in children: results of a multiinstitutional study (SJHG-98). Cancer 2005;103:133-139.

6. Tarnaris A, Edwards RJ, Lowis SP, Pople IK. Atypical external hydrocephalus with visual failure due to occult leptomeningeal dissemination of a pontine glioma: case report. J Neurosurg 2005;102(Suppl 2):S224-S227.

7. Brown PD, Buckner JC, O'Fallon JR, et al. Adult patients with supratentorial pilocytic astrocytomas: a prospective multicenter clinical trial. Int J Radiation Oncol Biol Phys 2004;58:1153-1160.

8. Buschmann U, Gers B, Hildebrandt G. Pilocytic astrocytomas with leptomeningeal dissemination: biological behavior, clinical course, and therapeutical options. Childs Nerv Syst 2003;19:298-304.
9. Figueiredo EG, Matushita H, Machado AG, Plese JP, Rosemberg S, Marino R. Leptomeningeal dissemination of pilocytic astrocytoma at diagnosis in childhood: two cases report. Arq Neuropsiquiatr 2003;61:842-847.

10. Zorlu F, Selek U, Akyuz C, Ozturk A, Soylemezoglu F, Akalan N. Spinal seeding of a pilocytic astrocytoma following multiple subtotal resections. Pediatr Neurosurg 2005;41:248-252.

11. Mishima K, Nakamura M, Nakamura H, Nakamura O, Funata N, Shitara N. Leptomeningeal dissemination of cerebellar pilocytic astrocytoma: case report. J Neurosurg 1992;77:788-791.

12. Franceschi E, Cavallo G, Scopece L, et al. Temozolomide-induced partial response in a patient with primary diffuse leptomeningeal gliomatosis. J Neurooncol 2005;73:261-264.

13. Pallud J, Devaux B, Daumas-Duport C, Oppenheim C, Roux FX. Glioma dissemination along the corticospinal tract. J Neurooncol 2005;73: 239-240. 